\title{
Beneficial effects of citrus juice fermented with Lactobacillus plantarum YIT 0132 on atopic dermatitis: results of daily intake by adult patients in two open trials
}

\author{
Naomi HARIMA-MIZUSAWA ${ }^{1 *}$, Keiko KAMACHI ${ }^{3}$, Mitsuyoshi KANO ${ }^{1}$, Daisuke NOZAKI ${ }^{2}$, Tatsuo UETAKE ${ }^{4}$, \\ Yuji YOKOMIZO ${ }^{4}$, Takayuki NAGINO ${ }^{1}$, Akira TANAKA $^{3}$, Kouji MIYAZAKI ${ }^{1}$ and Shinichiro NAKAMURA ${ }^{4}$ \\ ${ }^{1}$ Yakult Central Institute, 5-11 Izumi, Kunitachi-shi, Tokyo 186-8650, Japan \\ ${ }^{2}$ Yakult Honsha Co., Ltd., 1-19 Higashi Shimbashi 1-chome, Minato-ku, Tokyo 105-8660, Japan \\ ${ }^{3}$ Kagawa Nutrition University, 3-24-3 Komagome, Toshima-ku, Tokyo 170-8481, Japan \\ ${ }^{4}$ RIKEN Innovation Center, Nakamura Laboratory, 2-1 Hirosawa, Wako, Saitama 351-0198, Japan
}

Received June 4, 2015; Accepted September 28, 2015; Published online in J-STAGE October 27, 2015

This study aimed to examine whether daily intake of citrus juice containing heat-killed Lactobacillus plantarum YIT 0132 (LP0132-fermented juice) alleviates symptoms of atopic dermatitis. This was a natural extension of our previous study in which LP0132 was shown to enhance IL-10 production in vitro and LP0132-fermented juice was found to alleviate symptoms and enhance quality of life (QOL) in patients with Japanese cedar pollinosis. In two open trials, Trial 1 and Trial 2, 32 and 18 adult patients with mild to moderate atopic dermatitis consumed LP0132-fermented juice for 8 weeks. Skin conditions and QOL were subjectively evaluated using Skindex-16 before intake of the juice (Pretreatment), 8 weeks after starting intake (Treatment) and 8 weeks after termination of intake (Post-treatment). Blood parameters were also analyzed. Comparison of the Treatment and Post-treatment time points with the Pre-treatment time point revealed significant reductions in the Skindex-16 overall score and the 3 domain subscores (symptoms, emotions, and functioning domains) in both trials. Moreover, blood levels of eosinophil cationic protein (ECP), total immunoglobulin E (IgE) and specific IgEs for Japanese cedar and cypress pollen were significantly attenuated in Trial 2. The findings suggest that daily intake of citrus fermented juice containing heat-killed LP0132 has beneficial effects on symptoms and QOL in patients with mild to moderate atopic dermatitis due to an immunomodulatory effect via attenuation of IgE and ECP.

Key words: Lactobacillus plantarum, citrus juice, atopic dermatitis, Skindex-16, quality of life, immunoglobulin E, eosinophil cationic protein

\section{INTRODUCTION}

The number of patients complaining of allergic symptoms such as atopic dermatitis and pollinosis is on the increase [1]. Also, many patients experiencing allergyspecific symptoms often experience additional symptoms of headache, malaise, insomnia, frustration, and anxiety. Although these symptoms are not fatal, they significantly reduce quality of life (QOL), lowering working and

\footnotetext{
*Corresponding author. Mailing address: Naomi Harima-Mizusawa, Yakult Central Institute, 5-11 Izumi, Kunitachi-shi, Tokyo 186-8650, Japan. Phone: +81-42-577-8960, Fax: +81-42-5773020. E-mail: naomi-mizusawa@yakult.co.jp

(C)2016 BMFH Press

This is an open-access article distributed under the terms of the Creative Commons Attribution Non-Commercial No Derivatives (bync-nd) License $<$ http://creativecommons.org/licenses/by-nc-nd/4.0/>.
}

learning efficiency, and therefore they are becoming a major social problem [2,3]. In general, anti-allergy drugs such as antihistamines, steroids and immune suppressors are used to alleviate symptoms. However, such treatment is expensive, and long-term administration of these drugs frequently results in side effects. Prevention or improved treatment of allergies such as atopic dermatitis without drugs is therefore urgently required.

Recently, use of functional foods with anti-allergic activity for the treatment or prevention of allergies has attracted attention. For example, certain lactic acid bacteria (LAB) are known to show immunomodulatory effects [4-6], with several clinical trials demonstrating an effect in alleviating symptoms of pollinosis [7-10] and atopic dermatitis [11, 12]. Certain herbs and natural herbal products are also known to have anti-allergic potential. For example, hesperidin, a flavanone glycoside found in 
citrus fruits, has been found to have anti-inflammatory activity, inhibiting degranulation of mast cells, relieving edema and preventing anaphylaxis [13-15].

Previously, we reported on Lactobacillus plantarum YIT 0132 (LP0132), which shows high potential to proliferate in citrus juice. In mouse intraperitoneal macrophage culture, LP0132 was found to induce IL-10, which is an anti-inflammatory cytokine, and LP0132 and citrus juice were found to have an additional effect on allergic symptoms in an animal model of Japanese cedar pollinosis (JCPsis). A single-blind, placebo-controlled, parallel-group trial also revealed that daily intake of citrus juice fermented with LP0132 alleviates symptoms while enhancing QOL in patients with JCPsis [16]. However, it remains unknown whether citrus juice fermented with LP0132 also alleviates symptoms of atopic dermatitis in adult patients. To examine this question, we conducted two open trials of daily intake of citrus juice fermented with LP0132 in adult patients with atopic dermatitis.

\section{MATERIALS AND METHODS}

\section{Test beverage}

Satsuma Mandarin (Citrus unshiu) juice (Nankaikako Co., Ltd., Wakayama, Japan) was fermented with LP0132, obtained from the Culture Collection Research Laboratory of Yakult Central Institute, at $37^{\circ} \mathrm{C}$ for $48 \mathrm{hr}$ and then sterilized by heating at $90^{\circ} \mathrm{C}$ for $5 \mathrm{~min}$ (LP0132fermented juice). The composition of the resulting beverage is shown in Table 1. The final product contained LP0132 cells at a concentration of approximately $6 \times$ $10^{10}$ cells $/ 100 \mathrm{ml}$, as determined by the DAPI counting method [17]. The beverage was distributed and stored at $4^{\circ} \mathrm{C}$.

\section{Design}

The study consisted of two single-arm, nonrandomized, open trials, Trials 1 and 2, conducted from October to February in 2012 and 2013, respectively. Subjects were asked to consume a bottle $(100 \mathrm{ml})$ of test beverage once a day after breakfast from 13 October to 15 December 2012 in Trial 1, and from 21 October to 15 December 2013 in Trial 2 (Fig. 1).

\section{Subjects}

Male and female subjects aged 18 to 77 years with mild to moderate atopic dermatitis according to the 2008 guidelines for the treatment of atopic dermatitis [18] were recruited. In Trial 1, a total of 33 subjects (12 men, 21 women) were enrolled, with none meeting any of the exclusion criteria: severe atopic dermatitis,
Table 1. Composition of the test beverage in Trials 1 and 2

\begin{tabular}{lrc}
\hline Calories & $\mathrm{kcal} / 100 \mathrm{ml}$ & 39.0 \\
Protein & $\mathrm{g} / 100 \mathrm{ml}$ & 0.4 \\
Fat & $\mathrm{g} / 100 \mathrm{ml}$ & $<0.1$ \\
Carbohydrates & $\mathrm{g} / 100 \mathrm{ml}$ & 9.4 \\
Sodium & $\mathrm{g} / 100 \mathrm{ml}$ & $\mathrm{ND}$ \\
Heat-killed LP0132 & cells/100 ml & $6.0 \times 10^{10}$ \\
\hline ND: not detected & &
\end{tabular}

other dermatitis, food allergy, drug allergy, pregnant or lactating, planning to become pregnant, or severe diseases such as cancer, diabetes, disorders of the liver, kidneys, heart, respiratory system, endocrine system, metabolic disorders, or mental illness. In Trial 2, 19 subjects (6 men, 13 women) were enrolled from the 33 who participated in Trial 1 , and the exclusion criteria were again checked. In both trials, no dietary restrictions, medications, or hospital visits were required during the test period, and any notes of interest were recorded in a diary. Subjects were asked to self-record intake of the test beverage, diet, medicine usage, lifestyle habits and any adverse events that occurred. Subjects were recommended to follow an invariant lifestyle during the trial. Each trial was conducted in accordance with the Declaration of Helsinki, and all procedures involving human subjects were approved by the Human Trials Committee of Kagawa Nutrition University, Tokyo, Japan. Written informed consent was obtained from all subjects prior to enrollment in each trial.

\section{Evaluation of symptoms and $Q O L$}

Subjects were required to answer a questionnaire, the Skindex-16 (Table 3) [19-21], which was comprised of 16 items and scored on a 7-point scale ranging from 0 (never bothered) to 6 (always bothered), to evaluate symptoms of atopic dermatitis and reduced QOL prior to intake of the test beverage (Pre-treatment), 8 weeks after starting intake (Treatment), and 8 weeks after termination of intake (Post-treatment). In both trials, the overall score for all question items and the 3 domain subscores, that is the symptoms domain (items No. 1 to No. 4), the emotions domain (No. 5 to No. 11) and the functioning domain (No. 12 to No. 16), were analyzed to compare the Treatment and Post-treatment time points with the Pre-treatment time point.

\section{Photographs}

In Trial 1, photographs of the sites of symptoms were taken in all subjects at the Pre-treatment, Treatment and Post-treatment time points. 
Table 2. Background data of the subjects in Trials 1 and 2

\begin{tabular}{|c|c|c|c|c|c|c|}
\hline & \multicolumn{3}{|c|}{ Trial 1} & \multicolumn{3}{|c|}{ Trial 2} \\
\hline & Male & Female & Total & Male & Female & Total \\
\hline$n$ & 12 & 20 & 32 & 6 & 12 & 18 \\
\hline Age & $47.4 \pm 19.0$ & $42.4 \pm 11.1$ & $44.5 \pm 14.3$ & $50.3 \pm 21.3$ & $42.2 \pm 12.0$ & $43.1 \pm 14.0$ \\
\hline Height (cm) & $166.1 \pm 4.3$ & $159.0 \pm 4.7$ & $161.7 \pm 5.7$ & $165.2 \pm 4.3$ & $161.0 \pm 5.3$ & $162.2 \pm 5.5$ \\
\hline Weight (kg) & $67.0 \pm 14.9$ & $54.5 \pm 13.4$ & $59.2 \pm 15.0$ & $66.8 \pm 16.2$ & $51.1 \pm 9.2$ & $56.0 \pm 14.0$ \\
\hline BMI & $24.2 \pm 4.7$ & $21.5 \pm 4.9$ & $22.5 \pm 4.9$ & $24.3 \pm 4.8$ & $21.5 \pm 4.9$ & $19.7 \pm 2.4$ \\
\hline Body fat (\%) & $22.5 \pm 6.1$ & $29.1 \pm 8.1$ & $25.0 \pm 8.1$ & $22.1 \pm 5.3$ & $29.1 \pm 8.1$ & $24.8 \pm 5.7$ \\
\hline $\mathrm{DBP}(\mathrm{mmHg})$ & $77.6 \pm 15.7$ & $70.3 \pm 4.8$ & $73.0 \pm 14.3$ & $84.1 \pm 8.2$ & $70.3 \pm 4.8$ & $64.2 \pm 11.5$ \\
\hline $\mathrm{SBP}(\mathrm{mmHg})$ & $123.8 \pm 20.9$ & $114.2 \pm 17.9$ & $117.8 \pm 19.4$ & $127.3 \pm 18.0$ & $114.2 \pm 17.9$ & $104.7 \pm 13.7$ \\
\hline
\end{tabular}

Data are shown as the mean \pm standard deviation (SD). BMI: body mass index; DBP: diastolic blood pressure; SBP: systolic blood pressure

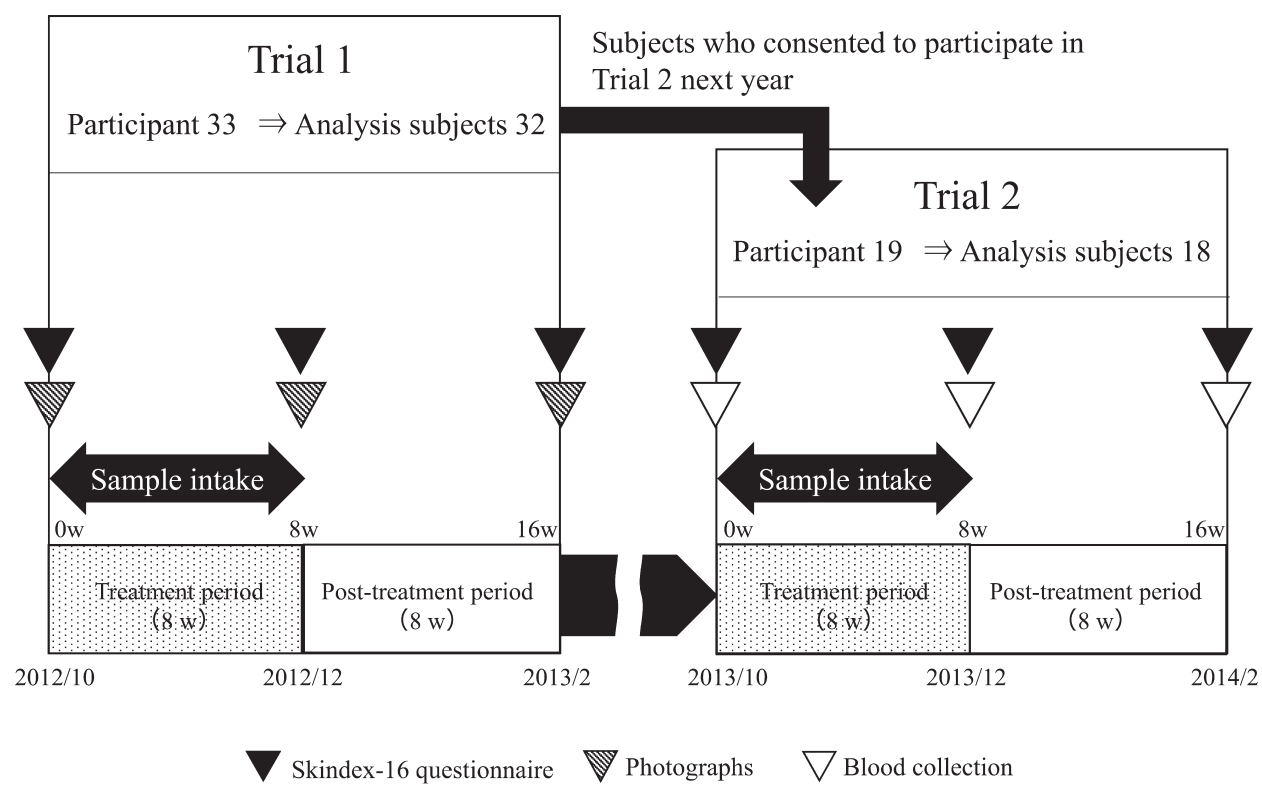

Fig. 1. Study protocol.

A total of 33 subjects who consented to participation in Trial 1 consumed the test beverage for 8 weeks and then underwent an 8-week Post-treatment period from Oct 2012 to Feb 2013. Of the Trial 1 subjects, 19 participated in Trial 2 (Oct 2013 to Feb 2014) after giving further consent. The protocol of Trial 2 was the same as that of Trial 1, except for photographs, which were taken in Trial 1 only, and blood samples, which were taken in Trial 2 only.

\section{Serum parameters}

In Trial 2, consent was obtained from 13 subjects for collection of blood samples at the Pre-treatment, Treatment and Post-treatment time points. Serum levels of immunoglobulin E (IgE) (total, specific for Japanese cedar pollen and specific for Japanese cypress pollen) and eosinophil cationic protein (ECP) were determined by fluorescent enzyme immunoassay. The percentages of Th1 cells (IFN- $\gamma+/ \mathrm{IL}-4-)$ /helper T cells (CD4+ T cells), Th2 cells (IFN- $\gamma-/$ IL-4+)/helper T cells (CD4+ T cells), Th1/Th2 and Treg cells (CD4+CD25+Foxp3+)/helper T cells (CD4+ T cells) were determined by flow cytometry using an automated hematology analyzer (Sysmex XE-2100, Sysmex Co., Ltd., Hyogo, Japan). General biochemical parameters in serum and hematologic parameters were also examined.

\section{Statistics}

Data are shown as the mean \pm standard deviation. All data were analyzed using the SAS preclinical package ver. 5.0 (SAS Institute Japan, Tokyo, Japan). Questionnaire data were analyzed by Wilcoxon signed- 
Table 3. Skindex-16 item

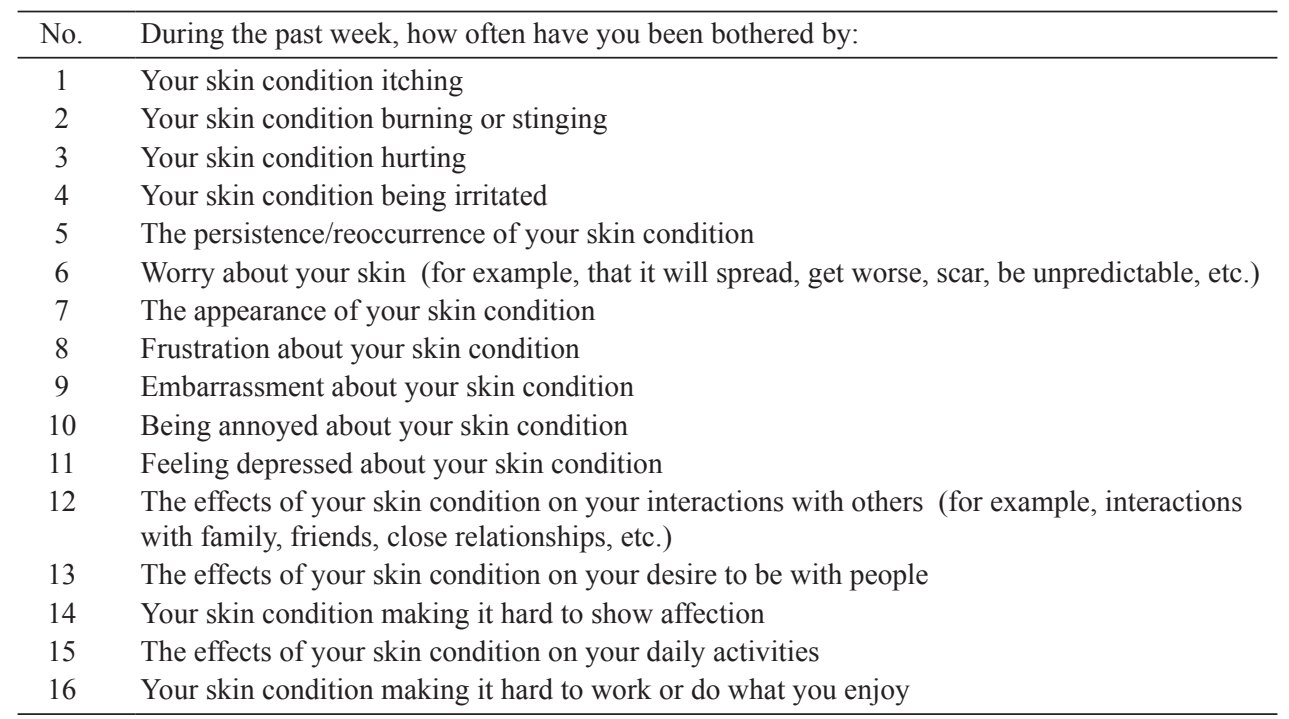

Each question asks the patient the degree to which they have been bothered about their skin condition, and each is graded on a 7-point scale ranging from 0 (never bothered) to 6 (always bothered).

rank test between the Pre-treatment time point and each analysis point. Blood data were analyzed by Wilcoxon signed-rank test between Pre-treatment and each analysis point. Multiple comparison was followed by Bonferroni correction. Two-sided p-values of $<0.05$ were considered statistically significant.

\section{RESULTS}

\section{Trial 1}

Inclusion of subjects

Figure 1 shows the inclusion of subjects. A total of 33 subjects consumed the test beverage for 8 weeks. One subject was unable to answer the questionnaire after treatment for personal reasons. The compliance rate was about $98 \%$, and no subjects recorded any adverse events or major changes in diet or lifestyle habits during the trial. As a result, 32 subjects (12 men, 20 women) were included in the final analysis after exclusion of the abovementioned subject. Background data of the subjects are shown in Table 2.

\section{Evaluation of symptoms and $Q O L$}

Figure 2-(a) shows the changes in overall score (average score of all items) in Trial 1. Compared with the Pre-treatment time point, the overall score was significantly reduced at the Treatment and Post-treatment time points $($ each $\mathrm{p}<0.0005$ ). Figure 3 -(a) shows the changes in the average domain subscores. Compared with the Pre-treatment time point, the symptoms domain $(p<0.005)$, emotions domain $(p<0.0005)$ and functioning domain $(p<0.005))$ were significantly lower at the Treatment time point. Also, compared with the Pretreatment time point, the symptoms domain $(\mathrm{p}<0.025)$, emotions domain $(\mathrm{p}<0.0005)$ and functioning domain $(p<0.005)$ were significantly lower at the Post-Treatment time point.

Table 4 shows the changes in score for each of the 16 items in Skindex-16. Compared with the Pre-treatment time point, the scores for item No. 1, No. 5 to 11, No. 15 (each $\mathrm{p}<0.0005)$, No. 4, No. 16 (each $\mathrm{p}<0.005)$ and No. $12(p<0.025)$ were significantly reduced at the Treatment time point. Also, the scores for item No. 7 to No. 11 (each $\mathrm{p}<0.0005$ ), No. 1 , No. 6, No. 15 (each $\mathrm{p}<0.005$ ) and No. 5 $(p<0.025)$ were significantly reduced at the Pre-treatment time point.

\section{Photographs}

In most photographs taken at the Pre-treatment time point, symptoms of atopic dermatitis were observed. In clear contrast, at the Treatment time point, symptoms were reduced in many subjects. Figure 4 shows representative photographs of this improvement for 3 subjects.

\section{Trial 2}

\section{Inclusion of subjects}

Figure 1 shows the inclusion of subjects. The compliance rate for intake of the test beverage was 


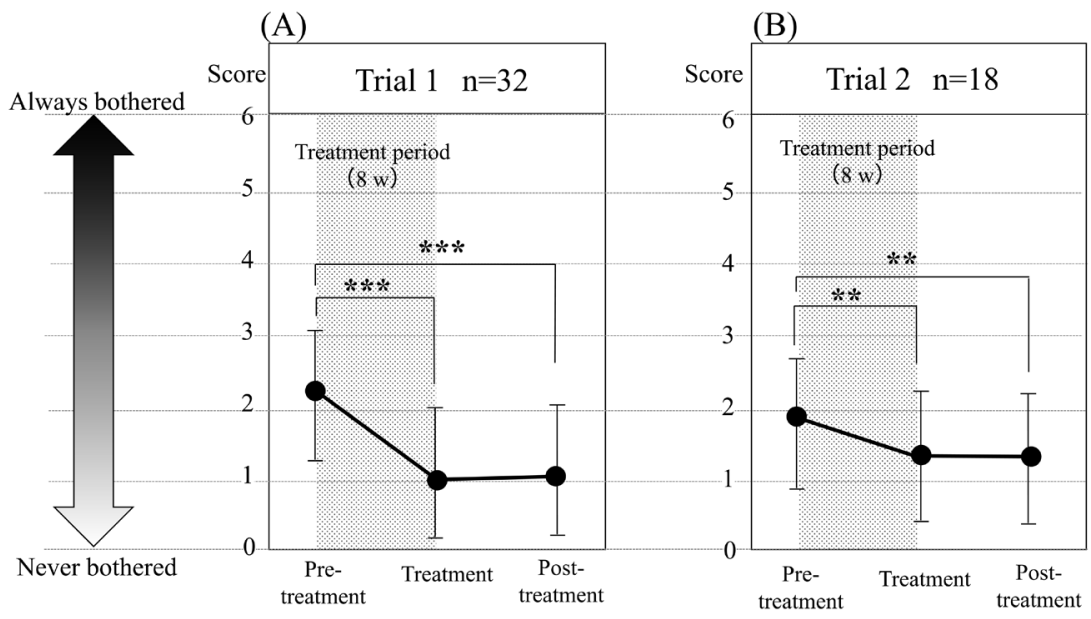

Fig. 2. Changes of overall score of Skindex-16 during Trials 1 and 2.

The effect of test beverage intake was evaluated by comparing scores at the Treatment and Post-treatment time points with those at the Pre-treatment time point, respectively. (A) Trial 1, (B) Trial 2. Data are shown as the mean \pm standard deviation (SD). Statistical difference were determined by Wilcoxon signed-rank test with Bonferroni correction (vs. Pre-treatment). ${ }^{*} \mathrm{p}<0.05 / 2 ;{ }^{* *} \mathrm{p}<0.01 / 2 ;{ }^{* * *} \mathrm{p}<0.001 / 2$.

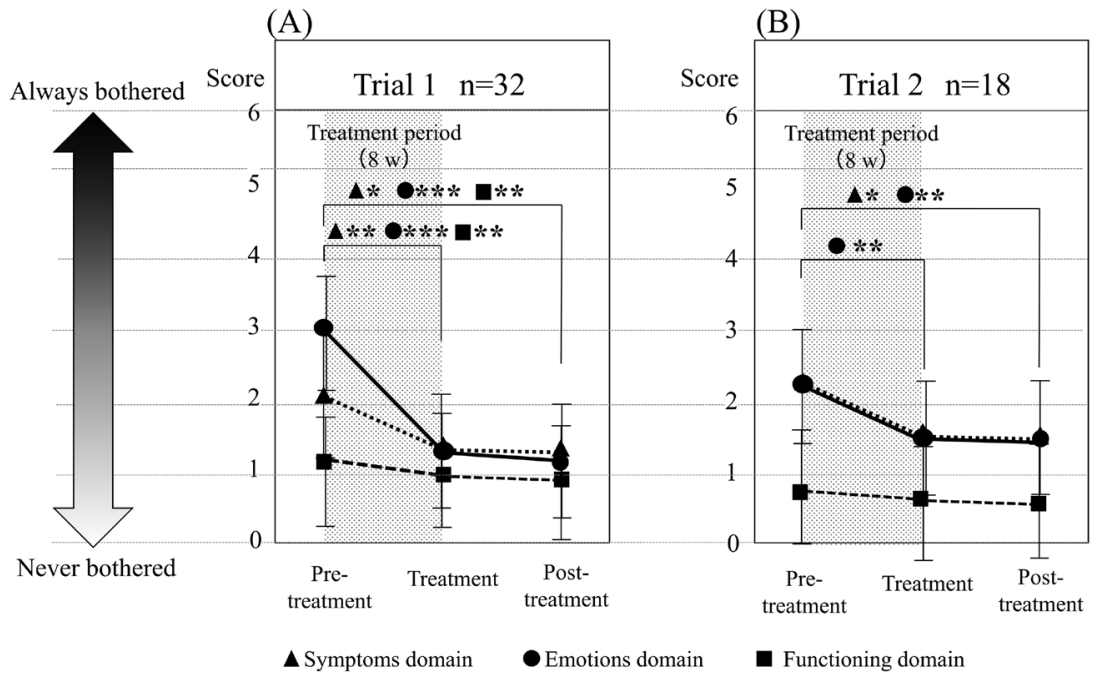

Fig. 3. Changes of three domain subscores of Skindex-16 during Trials 1 and 2.

The effect of test beverage intake was evaluated by comparing scores at the Treatment and Post-treatment time points with those at the Pre-treatment time point, respectively. (A) Trial 1, (B) Trial 2. Data are shown as the mean \pm SD. Statistical difference were determined by Wilcoxon signed-rank test with Bonferroni correction (vs. Pre-treatment), ${ }^{*} \mathrm{p}<0.05 / 2 ;{ }^{* *} \mathrm{p}<0.01 / 2 ;{ }^{* * *} \mathrm{p}<0.001 / 2$.

$100 \%$ during the intervention period, and no subject recorded any adverse events or major changes in diet or lifestyle habits during the trial. One subject whose biochemical measurements were abnormal was excluded at the discretion of the doctor. As a result, 18 subjects $(6$ men, 12 women) were included in the final analysis after exclusion of the abovementioned subject. Background data of the analysis subjects are shown in Table 2.

\section{Evaluation of symptoms and QOL in Skindex-16}

Figure 2-(b) shows the changes in overall score (average score for all items). Compared with the Pretreatment point time, the scores at the Treatment and Post-treatment time points were significantly reduced (each $\mathrm{p}<0.005$ ). Figure $3-(\mathrm{b})$ shows the changes in average domain subscores. At the Treatment time point, the emotions domain was significantly lower $(p<0.005)$ compared with the Pre-treatment time point. 
Table 4. Skindex-16 scores in Trial 1

\begin{tabular}{|c|c|c|c|c|c|c|}
\hline \multirow{2}{*}{ No. } & \multirow{2}{*}{ Items } & \multirow{2}{*}{ Pre-treatment } & \multicolumn{2}{|c|}{ Treatment } & \multicolumn{2}{|c|}{ Post-treatment } \\
\hline & & & Avg SD & p-value & Avg SD & p-value \\
\hline 1 & Itching & $3.8 \pm 1.8$ & $2.3 \pm 1.6$ & $0.0004 * * *$ & $2.3 \pm 1.9$ & $0.0032 * *$ \\
\hline 2 & Burning or stinging & $1.9 \pm 1.6$ & $1.3 \pm 1.6$ & 0.0624 & $1.2 \pm 1.6$ & 0.0675 \\
\hline 3 & Hurting & $1.3 \pm 1.4$ & $0.6 \pm 0.9$ & 0.0392 & $0.7 \pm 1.3$ & 0.1027 \\
\hline 4 & Being irritated & $2.0 \pm 1.6$ & $1.2 \pm 1.5$ & $0.0049 * *$ & $1.3 \pm 1.6$ & 0.0620 \\
\hline 5 & Persistence/reoccurrence & $3.4 \pm 2.2$ & $1.7 \pm 1.6$ & $0.0004 * * *$ & $1.9 \pm 1.7$ & $0.0100 *$ \\
\hline 6 & Worry & $3.1 \pm 2.2$ & $1.1 \pm 1.6$ & $<0.0001 * * *$ & $1.4 \pm 1.5$ & $0.0028 * *$ \\
\hline 7 & Appearance & $3.5 \pm 1.8$ & $1.6 \pm 1.6$ & $<0.0001 * * *$ & $1.5 \pm 1.6$ & $<0.0001 * * *$ \\
\hline 8 & Frustration & $2.7 \pm 1.9$ & $0.9 \pm 1.4$ & $<0.0001 * * *$ & $0.9 \pm 1.3$ & $<0.0001 * * *$ \\
\hline 9 & Embarrassment & $2.8 \pm 1.9$ & $1.2 \pm 1.4$ & $<0.0001 * * *$ & $0.9 \pm 1.5$ & $<0.0001 * * *$ \\
\hline 10 & Being annoyed & $3.6 \pm 2.1$ & $1.7 \pm 1.9$ & $<0.0001 * * *$ & $1.2 \pm 1.6$ & $<0.0001 * * *$ \\
\hline 11 & Feeling depressed & $2.5 \pm 2.1$ & $0.9 \pm 1.4$ & $0.0003^{* * *}$ & $0.7 \pm 1.1$ & $0.0004 * * *$ \\
\hline 12 & Affecting interactions with others & $0.9 \pm 1.2$ & $0.3 \pm 0.7$ & $0.0193^{*}$ & $0.4 \pm 0.8$ & 0.0495 \\
\hline 13 & Desire to be with people & $0.8 \pm 1.1$ & $0.3 \pm 0.7$ & 0.0540 & $0.4 \pm 0.8$ & 0.1762 \\
\hline 14 & Show affection & $0.6 \pm 1.0$ & $0.3 \pm 0.7$ & 0.1123 & $0.4 \pm 0.8$ & 0.3150 \\
\hline 15 & Daily activities & $1.8 \pm 1.7$ & $0.6 \pm 1.0$ & $0.0003 * * *$ & $0.6 \pm 1.0$ & $0.0008 * *$ \\
\hline 16 & Work or do what you enjoy & $1.2 \pm 1.4$ & $0.4 \pm 0.9$ & $0.0022 * *$ & $0.5 \pm 1.0$ & 0.0415 \\
\hline
\end{tabular}

Skindex-16 scores for 32 subjects. Data are shown as the shown as mean \pm SD. The Pre-treatment time point was compared with the Treatment and Post-treatment time points by Wilcoxon signed-rank test with Bonferroni correction (vs. Pre-treatment). ${ }^{*} \mathrm{p}<0.05 / 2$; $* * \mathrm{p}<0.01 / 2 ; * * * \mathrm{p}<0.001 / 2$

\begin{tabular}{|c|c|c|c|}
\hline & Pre-treatment & Treatment & Post-treatment \\
\hline $\begin{array}{c}(\mathrm{A}) \\
\text { 34-year-old } \\
\text { Male }\end{array}$ & & & \\
\hline $\begin{array}{c}(\mathrm{B}) \\
\text { 74-year-old } \\
\text { Male }\end{array}$ & & & \\
\hline $\begin{array}{c}(\mathrm{C}) \\
\text { 51-year-old } \\
\text { Female }\end{array}$ & & & \\
\hline
\end{tabular}

Fig. 4. Representative photographs of skin lesions after treatment with LP0132-fermented juice during Trial 1.

(A) A 34-year-old man (subject No. 34) with erythema and exanthema. (B) A 74 year-old male (subject No. 16) with scaling and desquamation. (C) A 51 year-old female (subject No. 05) with slight erythema and exanthema. Almost all subjects showed significant improvement of skin lesions after treatment.

Also, at the Post-Treatment time point, the symptoms domain $(p<0.025)$ and emotions domain $(p<0.005)$ were significantly lower compared with the Pre-treatment time point. Table 5 shows the changes in score for each of the 16 items in Skindex-16. Compared with the Pretreatment time point, the scores for item No. $7(p<0.005)$,
No. 5, No. 6, No. 11 and No. 12 (each $\mathrm{p}<0.025)$ were significantly reduced at the Treatment time point. The scores for item No. 1, No. 7 (each $\mathrm{p}<0.005)$, No. 5, No. 7, No. 9 and No. 13 (each $\mathrm{p}<0.025)$ were significantly reduced at the Pre-treatment time point. 
Table 5. Skindex-16 scores in Trial 2

\begin{tabular}{|c|c|c|c|c|c|c|}
\hline \multirow{2}{*}{ No. } & \multirow{2}{*}{ Items } & \multirow{2}{*}{ Pre-treatment } & \multicolumn{2}{|c|}{ Treatment } & \multicolumn{2}{|c|}{ Post-treatment } \\
\hline & & & Avg SD & p-value & Avg SD & p-value \\
\hline 1 & Itching & $3.2 \pm 1.5$ & $2.4 \pm 1.8$ & 0.0322 & $2.5 \pm 1.6$ & $0.0006^{* *}$ \\
\hline 2 & Burning or stinging & $2.4 \pm 1.8$ & $1.7 \pm 1.6$ & 0.1202 & $1.8 \pm 1.6$ & 0.0571 \\
\hline 3 & Hurting & $1.6 \pm 1.5$ & $1.1 \pm 1.5$ & 0.1682 & $1.1 \pm 1.2$ & 0.0863 \\
\hline 4 & Being irritated & $1.9 \pm 1.8$ & $1.4 \pm 1.6$ & 0.2129 & $1.3 \pm 1.3$ & 0.0281 \\
\hline 5 & Persistence/reoccurrence & $2.9 \pm 1.8$ & $2.1 \pm 1.8$ & $0.0235^{*}$ & $2.0 \pm 1.7$ & $0.0123 *$ \\
\hline 6 & Worry & $2.4 \pm 2.1$ & $1.8 \pm 1.9$ & $0.0197 *$ & $1.8 \pm 1.9$ & 0.0334 \\
\hline 7 & Appearance & $2.7 \pm 1.9$ & $1.8 \pm 1.6$ & $0.0031 * *$ & $1.9 \pm 1.8$ & $0.0116^{*}$ \\
\hline 8 & Frustration & $1.7 \pm 1.8$ & $1.2 \pm 1.6$ & 0.0391 & $1.1 \pm 1.4$ & $0.002 * *$ \\
\hline 9 & Embarrassment & $2.0 \pm 2.0$ & $1.5 \pm 1.8$ & 0.0938 & $1.3 \pm 1.6$ & $0.0215^{*}$ \\
\hline 10 & Being annoyed & $2.7 \pm 2.1$ & $2.2 \pm 2.1$ & 0.0654 & $2.0 \pm 1.9$ & 0.0450 \\
\hline 11 & Feeling depressed & $1.6 \pm 1.8$ & $0.9 \pm 1.2$ & $0.0234 *$ & $1.2 \pm 1.4$ & 0.2148 \\
\hline 12 & Affecting interactions with others & $0.7 \pm 1.2$ & $0.3 \pm 0.8$ & $0.0156^{*}$ & $0.4 \pm 0.8$ & 0.0469 \\
\hline 13 & Desire to be with people & $0.6 \pm 1.1$ & $0.4 \pm 0.9$ & 0.2031 & $0.4 \pm 0.8$ & $0.0156^{*}$ \\
\hline 14 & Show affection & $0.5 \pm 1.0$ & $0.3 \pm 0.8$ & 0.1875 & $0.3 \pm 0.8$ & 0.2656 \\
\hline 15 & Daily activities & $0.8 \pm 1.2$ & $0.6 \pm 1.0$ & 0.0938 & $0.4 \pm 1.0$ & 0.1563 \\
\hline 16 & Work or do what you enjoy & $0.6 \pm 1.2$ & $0.4 \pm 1.0$ & 0.5000 & $0.4 \pm 1.0$ & 0.2500 \\
\hline
\end{tabular}

Skindex-16 scores for 18 subjects. Data are shown as the mean \pm SD. The Pre-treatment time point was compared with the Treatment and Post-treatment time point by Wilcoxon signed-rank test with Bonferroni correction (vs. Pre-treatment). $* \mathrm{p}<0.05 / 2 ; * * \mathrm{p}<0.01 / 2 ; * * \mathrm{p}<0.001 / 2$

\section{Serum parameters}

Table 6 shows the data for serum parameters as the mean \pm standard deviation in 13 subjects who consented to collection of blood samples. Compared with the Pretreatment time point, the serum levels of specific IgEs for Japanese cedar pollen and Japanese cypress pollen, detected in 9 subjects, were significantly reduced at Treatment and Post-treatment (each $\mathrm{p}<0.005)$. In contrast, specific IgEs for mite and house dust, considerable antigens of atopic dermatitis, were detected in 7 subjects. The levels were reduced at the Treatment and Posttreatment time points, however, the differences were not significant. The serum levels of ECP were significantly reduced at the Treatment $(\mathrm{p}<0.025)$ and Post-treatment time points $(p<0.0005)$. Also, serum total IgE was significantly reduced at the Post-treatment time point $(\mathrm{p}<0.0005)$. However, there were no significant changes in the percentage of Th1/helper $\mathrm{T}$ cells, Th2/helper $\mathrm{T}$ cells, Th1/Th2 and Treg/helper T cells during the trial.

\section{DISCUSSION}

To determine whether LP0132-fermented juice alleviates symptoms of atopic dermatitis, two singlearm, non-randomized, open trials, Trials 1 and 2, were conducted with overlapping adult subjects with mild to moderate atopic dermatitis. The same design was used for 2 consecutive years. The present study demonstrated that daily intake of LP0132-fermented juice significantly reduced the overall score (Fig. 2) and the subscore for the emotions domain (Fig. 3) in Skindex-16 compared with the scores before intake (Pre-treatment) in both trials. In Trial 1, a distinct improvement was observed in some subjects (Fig. 4), whose QOLs were also remarkably enhanced. These findings suggest that LP0132-fermented juice has the potential to improve symptoms in adult patients with mild to moderate atopic dermatitis.

In Japan, there are seasonal variations in factors such as dryness, heavy sweating and pollen dispersal that aggravate symptoms of atopic dermatitis. Many patients with atopic dermatitis experience aggravated symptoms during the dry winter months [22]. Accordingly, both trials were conducted from October to February to avoid heavy sweating and pollen dispersal. That is, the period between the Treatment and Post-treatment time points was a dry season (December to February). Interestingly, significant reductions in overall score (Fig. 2) and subscores for the emotions domain (Fig. 3) in Skindex-16 were observed and maintained at a constant level for 8 weeks, even after termination of daily intake of the test beverage (between the Treatment and Post-treatment time points) in both trials. Moreover, exploratory analysis of 18 subjects in Trial 2 was conducted to compare scores between the Treatment time point in Trial 1 and Pre-treatment time point in Trial 2 using the Wilcoxon signed-rank test (Table 7). The results were significantly higher at the 
Table 6. The allergy related parameters of blood samples in Trial 2

\begin{tabular}{|c|c|c|c|c|c|c|c|}
\hline & & \multirow{2}{*}{$\begin{array}{c}\text { Number of } \\
\text { detected } \\
\text { subject }\end{array}$} & \multirow{2}{*}{ Pre-treatment } & \multicolumn{2}{|l|}{ Treatment } & \multicolumn{2}{|c|}{ Post-treatment } \\
\hline & & & & Avg SD & p-value & Avg & $\mathrm{p}$-value \\
\hline Th1 (IFN+/IL4-) & $(\%)$ & & $16.5 \pm 7.9$ & $16.5 \pm 6.92$ & 0.9097 & $16.15 \pm 7.43$ & 1 \\
\hline Th2 (IFN-/IL4+) & $(\%)$ & & $1.1 \pm 0.47$ & $0.81 \pm 0.23$ & 0.0566 & $0.9 \pm 0.4$ & 0.292 \\
\hline Th1/Th2 & $(\%)$ & & $21.58 \pm 27.34$ & $23.69 \pm 17.16$ & 0.0923 & $23.28 \pm 20.92$ & 0.8394 \\
\hline Treg (CD25+Foxp3+) & $(\%)$ & & $1.48 \pm 0.63$ & $1.44 \pm 0.68$ & 0.6848 & $1.63 \pm 0.92$ & 0.6848 \\
\hline Total IgE & $(\mathrm{IU} / \mathrm{ml})$ & & $314.62 \pm 352.48$ & $285.23 \pm 308.14$ & 0.105 & $227.31 \pm 232.23$ & $0.0005 * * *$ \\
\hline $\begin{array}{l}\text { Specific IgE for Japanese cedar } \\
\text { pollen }\end{array}$ & $(\mathrm{IU} / \mathrm{ml})$ & 9 & $30.31 \pm 33.44$ & $22.87 \pm 27.74$ & $0.0039 * *$ & $18.65 \pm 22.02$ & $0.0039 * *$ \\
\hline $\begin{array}{l}\text { Specific IgE for Japanese cypress } \\
\text { pollen }\end{array}$ & $(\mathrm{IU} / \mathrm{ml})$ & 9 & $1.97 \pm 3.6$ & $1.53 \pm 2.73$ & $0.0039 * *$ & $1.17 \pm 1.98$ & $0.0039 * *$ \\
\hline Specific IgE for mites & $(\mathrm{IU} / \mathrm{ml})$ & 7 & $24.04 \pm 34.67$ & $25.69 \pm 37.34$ & 0.375 & $21.78 \pm 29.91$ & 0.1094 \\
\hline Specific IgE for house dust & $(\mathrm{IU} / \mathrm{ml})$ & 7 & $24.26 \pm 34.94$ & $25.09 \pm 37.23$ & 0.2188 & $19.66 \pm 26.91$ & 0.1094 \\
\hline $\mathrm{ECP}$ & $(\mu \mathrm{g} / \mathrm{l})$ & & $15.74 \pm 13.53$ & $10.4 \pm 8.13$ & $0.0105^{*}$ & $6.58 \pm 5.59$ & $0.0002 * * *$ \\
\hline
\end{tabular}

Blood samples were taken from 13 subjects. Data are shown as the mean \pm SD. Specific IgEs for Japanese cedar pollen and Japanese cypress pollen were not detected in 4 subjects. Specific IgEs for mites and house dust were not detected in 6 subjects. The Pre-treatment time point was compared with the Treatment and Post-treatment time points by paired t-test with Bonferroni correction (vs. Pre-treatment), ${ }^{*} \mathrm{p}<0.05 / 2 ; * * \mathrm{p}<0.01 / 2$; $* * * \mathrm{p}<0.001 / 2$

Table 7. Comparison of Skindex-16 scores between the Treatment time point in Trial 1 and Pre-treatment time point in Trial 2

\begin{tabular}{lcccc}
\hline & Treatment in Trial 1 & & \multicolumn{2}{c}{ Pre-treatment in Trial 2 } \\
\cline { 2 - 4 } \cline { 5 - 6 } & Avg SD & & Avg SD & p-value \\
\hline Symptoms domain score & $1.40 \pm 1.38$ & & $2.28 \pm 1.56$ & $0.0315^{*}$ \\
Emotions domain score & $1.38 \pm 1.40$ & & $2.30 \pm 1.78$ & $0.0037^{*}$ \\
Functioning domain score & $0.28 \pm 0.58$ & & $0.64 \pm 1.09$ & $0.0234^{*}$ \\
Overall score & $1.04 \pm 0.99$ & & $1.78 \pm 1.33$ & $0.002^{* *}$ \\
\hline
\end{tabular}

Exploratory analysis was performed for 18 subjects who participated in both trials to examine the changes that occurred in the period when the test beverage was not consumed (between the Treatment time point in Trial 1 and the Pre-treatment time point in Trial 2). Data are shown as the mean \pm SD. Statistical differences were assessed by Wilcoxon signed-rank test (vs. Treatment time point in Trial 1). ${ }^{*} \mathrm{p}<0.05 ; * * \mathrm{p}<0.01$

Pre-treatment time point in Trial 2 than at the Treatment time point in Trial 1 for overall score $(\mathrm{p}=0.0020)$, the symptoms domain $(\mathrm{p}=0.0315)$, emotions domain $(\mathrm{p}=0.0037)$ and the functioning domain $(\mathrm{p}=0.0234)$. These findings suggest that the improvements due to consuming LP0132-fermented juice occurred not because of seasonal changes or temporary remission, but rather because of a persistent effect lasting for at least the 8 weeks after termination of daily intake. However, it is prudent to consider that the potential for improvement possibly decreased by about 10 months after terminating daily intake, since data were not available for this time frame.

Changes in score for the 16 items of Skindex-16 showed a significant reduction in scores for all 7 emotions domain items, "persistence/reoccurrence," "worry," "appearance," "frustration," "embarrassment," "being annoyed" and "feeling depressed"; 2 symptom domain items, "itching" and "being irritated"; and 3 functioning domain items, "affecting interactions with others," "daily activity" and "work or do what you enjoy" at the Treatment time point in Trial 1 . There were also significant reductions in scores for "persistence/ reoccurrence," "worry," "appearance" and "feeling depressed" in the emotions domain and "affecting interactions with others" in the functioning domain at the Treatment time point in Trial 2. As mentioned above, the emotions domain subscore showed the lowest p-value among all scores of Skindex-16 between the Treatment time point in Trial 1 and the Pre-treatment time point in Trial 2 (Fig. 5). These findings suggest that the emotions domain is largely affected by improvement and 


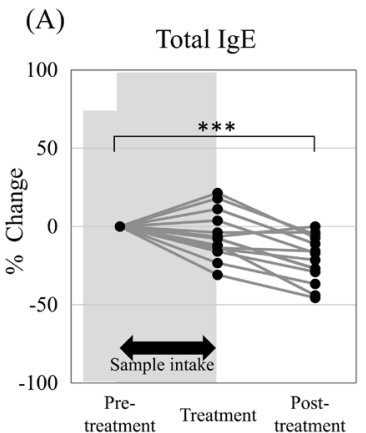

(C)
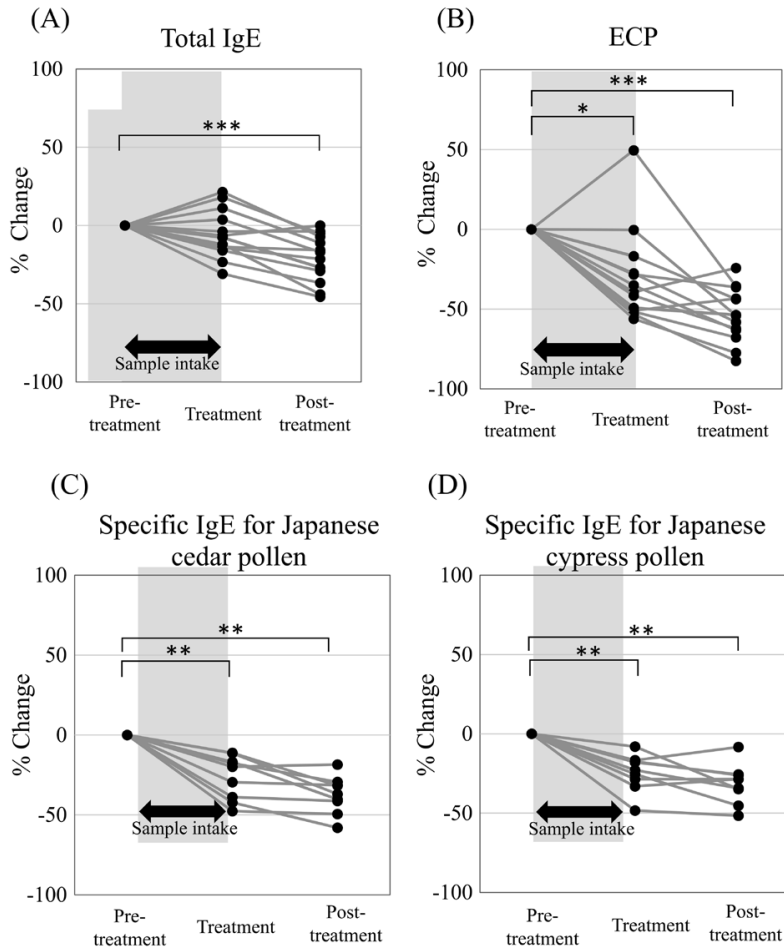

(D)

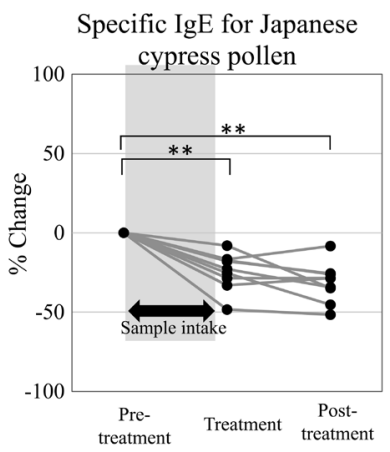

Fig. 5. Relative changes in immune-related parameters during Trial 2.

Values at the Pre-treatment time point were defined as baseline. The dot plots represent the relative changes in parameters at the Treatment and Post-treatment time points compared with the Pre-treatment time point. The effect of test beverage intake was evaluated by comparing changes at the Treatment and Post-treatment time points with those at the Pre-treatment time point. (A) Eosinophil cationic protein (ECP), (B) total immunoglobulin E (IgE), (C) Specific IgE for Japanese cedar pollen, (D) Specific IgE for Japanese cypress pollen. Statistical differences were determined by Wilcoxon signed-rank test with Bonferroni correction (vs. Pre-treatment). ${ }^{*} \mathrm{p}<0.05 / 2 ;{ }^{* *} \mathrm{p}<0.01 / 2$; $* * * \mathrm{p}<0.001 / 2$.

aggravation of atopic dermatitis. The improvement in these items with daily intake of LP0132-fermented juice therefore plays an important role in enhancing QOL in patients.

Of 13 subjects who participated in Trials 1 and 2 and consented to collection of blood samples, a reduction in the symptoms domain subscore was observed in 10 subjects in both trials and in 2 subjects in either Trial 1 or 2. One subject (ID No. 03) did not show any improvement in either trial (Fig. 6). Moreover, of all 13 subjects who participated in blood parameter analysis in Trial 2, specific IgEs for Japanese cedar pollen and Japanese cypress pollen were detected in the same 9 subjects, and the levels were reduced. ECP was also improved, with the exception of one subject (ID No. 03) (Fig. 7). In contrast,

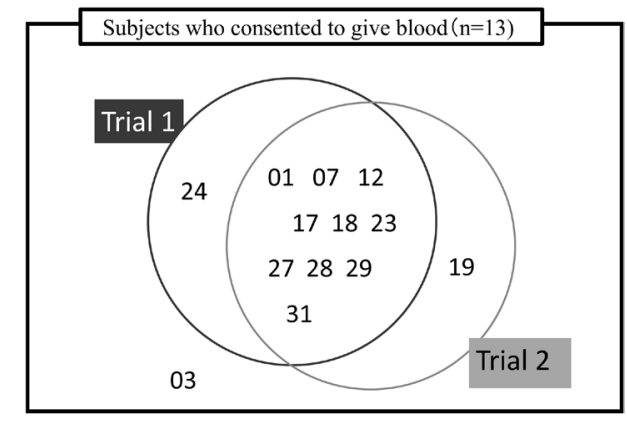

Fig. 6. Subjects showing improvement of the symptoms domain subscore in Skindex-16 in Trials 1 and 2.

ID numbers of subjects showing improvements compared with the Pre-treatment time point in Trial 1 and Trial 2 are shown within circles.

the 5 other subjects who participated in Trials 1 and 2 and did not consent to collection of blood samples showed a reduction in the symptom domain subscore in both trials. It appears that all 18 subjects who participated in Trials 1 and 2 responded well to the LP0132-fermented juice, although some may have experienced a time lag or low symptoms subscore at the Pre-treatment time point.

It has already been reported that $\mathrm{LAB}$ alleviates symptoms of atopic dermatitis in children [11] as well as adult subjects [12]. However, to the best of our knowledge, no clinical studies have demonstrated a significant improvement due to LAB treatment in both symptoms and blood parameters of atopic dermatitis. This study demonstrated that daily intake of LP0132fermented juice significantly reduced serum levels of IgE, especially in specific IgEs for Japanese cedar pollen and Japanese cypress pollen. Decreasing trends in specific IgEs for mites and house dust were also observed at the Treatment and Post-treatment time points. The levels of ECP decreased at the Treatment and Post-treatment time points. Our previous study found significant attenuation of serum total IgE, various specific IgEs and ECP in subjects with perennial allergic rhinitis [23]. These observations suggest that LP0132-fermented juice supports improvement of allergy symptoms through reduction of ECP and $\mathrm{IgE}$.

Our previous report showned that LP0132 stimulates IL-10 production in vitro [16]. It has been reported that IL-10 suppress IgE production from B cells [24, 25]. Thus, IL-10 may be involved in the possible mechanism of LP0132 inducing alterations in serum $\operatorname{IgE}$ levels. However, in the present study, the serum levels of IL-10 were below the detection limit in all subjects. Ohmen et al. [26] reported that IL-10 mRNA is over-repressed in 
(A)

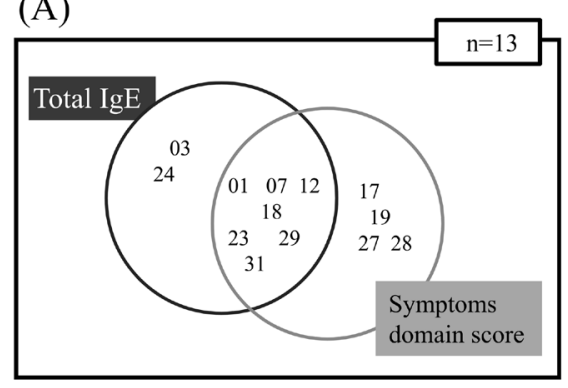

(C)

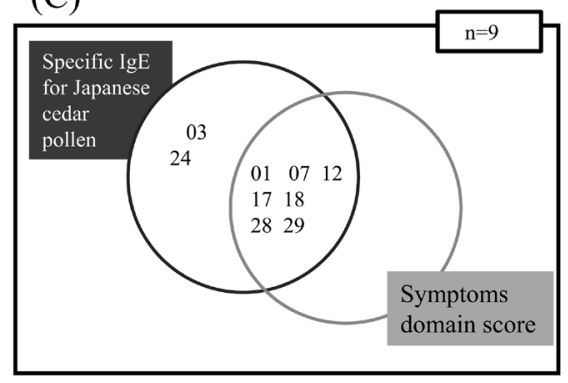

(B)

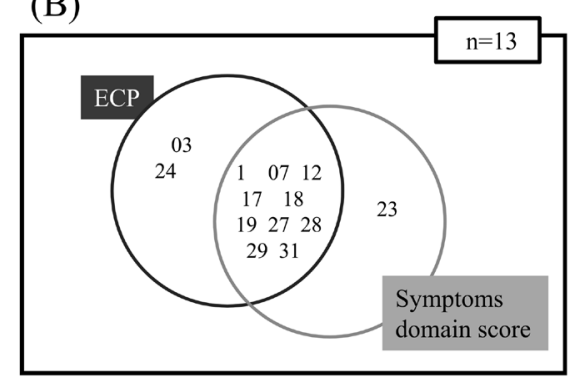

(D)

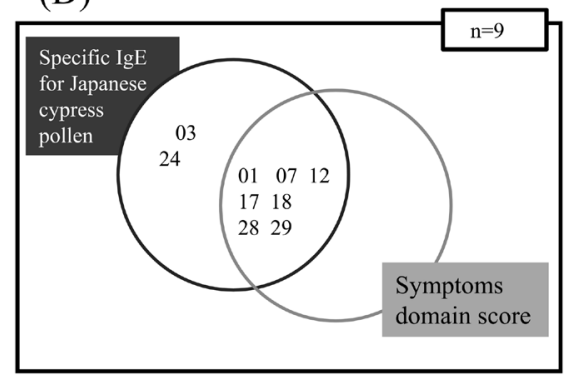

Fig. 7. Subjects showing improvement of the symptoms domain subscore in Skindex-16 and blood parameters in Trial 2 compared with the Pre-treatment time point.

(A) Eosinophil cationic protein (ECP), (B) Total immunoglobulin E (IgE), (C) Specific IgE for Japanese cedar pollen, (D) Specific IgE for Japanese cypress pollen. ID numbers of subjects showing improvements compared with the Pre-treatment time point in Trial 2 are shown within circles.

the skin lesion of patients with atopic dermatitis. It may be that IL-10 was induced from intestinal immune cells by LP0132 and that the levels increased in only local sites such as the skin lesion of atopic dermatitis.

Kaji et al. [5] reported that teichoic acids and the conformation of the cell wall of L. plantarum play an important role in inducing IL-10 production. Therefore, it is speculated that the cell wall of LP0132 is a major active component in the fermented juice. Hesperidin has also been reported to exert anti-allergy activity in vitro and in animal models [13, 14]. Citrus juice-derived components and fermented products might have minor roles, and it might be possible that the combination of them results in synergistic or additive anti-allergy effects.

In conclusion, this study demonstrated that daily intake of fermented citrus juice containing heat-killed LP0132 has beneficial effects on symptoms and QOL in patients with mild to moderate atopic dermatitis due to immunomodulating activity via the attenuation of $\operatorname{IgE}$ and ECP. Further studies are now necessary to obtain further evidence in a double-blind, placebo-controlled trial and to clarify the mechanism both in vitro and in animal studies.

\section{ACKNOWLEDGEMENTS}

We thank all the volunteers who enrolled in the clinical trial. We also thank Dr. K. Shida and Dr. N. Kubota of the Yakult Central Institute, Ms. M. Isozaki, Ms. C. Suzuki, and Ms. C. Kasuga of Kagawa Nutrition University and Ms. Y. Tamashiro of RIKEN for their technical support and helpful advice.

\section{REFERENCES}

1. Japanese guideline for the diagnosis and treatment of allergic diseases 2010 (in Japanese).

2. Murota H, Kitaba S, Tani M, Wataya-Kaneda M, Azukizawa H, Tanemura A, Umegaki N, Terao M, Kotobuki Y, Katayama I, Leynaert B. 2010. Impact of sedative and non-sedative antihistamines on the impaired productivity and quality of life in patients with pruritic skin diseases. Allergol Int 59: 345-354. [Medline] [CrossRef]

3. Leynaert B, Neukirch C, Liard R, Bousquet J, Neukirch F. 2000. Quality of life in allergic rhinitis and asthma. A population-based study of young adults. Am J Respir Crit Care Med 162: 1391-1396. [Medline] [CrossRef]

4. Shida K, Kiyoshima-Shibata J, Nagaoka M, Watanabe K, Nanno M. 2006. Induction of interleukin-12 by Lactobacillus strains having a rigid cell wall resistant to intracellular digestion. J Dairy Sci 89: 3306-3317. 
[Medline] [CrossRef]

5. Kaji R, Kiyoshima-Shibata J, Nagaoka M, Nanno M, Shida K. 2010. Bacterial teichoic acids reverse predominant IL-12 production induced by certain lactobacillus strains into predominant IL-10 production via TLR2-dependent ERK activation in macrophages. J Immunol 184: 3505-3513. [Medline] [CrossRef]

6. Nonaka $\mathrm{Y}$, Izumo $\mathrm{T}$, Izumi $\mathrm{F}$, Maekawa $\mathrm{T}$, Shibata H, Nakano A, Kishi A, Akatani K, Kiso Y. 2008. Antiallergic effects of Lactobacillus pentosus strain S-PT84 mediated by modulation of Th1/Th2 immunobalance and induction of IL-10 production. Int Arch Allergy Immunol 145: 249-257. [Medline] [CrossRef]

7. Xiao JZ, Kondo S, Yanagisawa N, Takahashi N, Odamaki T, Iwabuchi N, Miyaji K, Iwatsuki K, Togashi H, Enomoto K, Enomoto T. 2006. Probiotics in the treatment of Japanese cedar pollinosis: a doubleblind placebo-controlled trial. Clin Exp Allergy 36: 1425-1435. [Medline] [CrossRef]

8. Ishida $\mathrm{Y}$, Nakamura F, Kanzato H, Sawada D, Yamamoto N, Kagata H, Oh-Ida M, Takeuchi H, Fujiwara S. 2005. Effect of milk fermented with Lactobacillus acidophilus strain L-92 on symptoms of Japanese cedar pollen allergy: a randomized placebocontrolled trial. Biosci Biotechnol Biochem 69: 1652-1660. [Medline] [CrossRef]

9. Nagata Y, Yoshida M, Kitazawa H, Araki E, Gomyo T. 2010. Improvements in seasonal allergic disease with Lactobacillus plantarum No. 14. Biosci Biotechnol Biochem 74: 1869-1877. [Medline] [CrossRef]

10. Tamura M, Shikina T, Morihana T, Hayama M, Kajimoto O, Sakamoto A, Kajimoto Y, Watanabe O, Nonaka C, Shida K, Nanno M. 2007. Effects of probiotics on allergic rhinitis induced by Japanese cedar pollen: randomized double-blind, placebocontrolled clinical trial. Int Arch Allergy Immunol 143: 75-82. [Medline] [CrossRef]

11. Inoue $Y$, Kambara $T$, Murata N, Komori-Yamaguchi J, Matsukura S, Takahashi Y, Ikezawa Z, Aihara M. 2014. Effects of oral administration of Lactobacillus acidophilus L-92 on the symptoms and serum cytokines of atopic dermatitis in Japanese adults: a double-blind, randomized, clinical trial. Int Arch Allergy Immunol 165: 247-254. [Medline]

12. Yang HJ, Min TK, Lee HW, Pyun BY. 2014. Efficacy of probiotic therapy on atopic dermatitis in children: a randomized, double-blind, placebo-controlled trial. Allergy Asthma Immunol Res 6: 208-215. [Medline] [CrossRef]

13. Emim JA, Oliveira AB, Lapa AJ. 1994. Pharmacological evaluation of the anti-inflammatory activity of a citrus bioflavonoid, hesperidin, and the isoflavonoids, duartin and claussequinone, in rats and mice. J Pharm Pharmacol 46: 118-122. [Medline] [CrossRef]

14. Wei D, Ci X, Chu X, Wei M, Hua S, Deng X. 2012.
Hesperidin suppresses ovalbumin-induced airway inflammation in a mouse allergic asthma model. Inflammation 35: 114-121. [Medline] [CrossRef]

15. Kobayashi S, Tanabe S. 2006. Evaluation of the antiallergic activity of Citrus unshiu using rat basophilic leukemia RBL-2H3 cells as well as basophils of patients with seasonal allergic rhinitis to pollen. Int J Mol Med 17: 511-515. [Medline]

16. Harima-Mizusawa N, Iino $T$, Onodera-Masuoka $N$, Kato-Nagaoka N, Kiyoshima-Shibata J, Gomi A, Shibahara-Sone H, Kano M, Shida K, Sakai M, Miyazaki K, Ishikawa F. 2014. Beneficial effects of Citrus juice fermented with Lactobacillus plantarum YIT 0132 on Japanese cedar pollinosis. Biosci Microbiota Food Health 33: 147-155. [Medline] [CrossRef]

17. Matsuki T, Watanabe K, Fujimoto J, Miyamoto Y, Takada T, Matsumoto K, Oyaizu H, Tanaka R. 2002. Development of $16 \mathrm{~S}$ rRNA-gene-targeted groupspecific primers for the detection and identification of predominant bacteria in human feces. Appl Environ Microbiol 68: 5445-5451. [Medline] [CrossRef]

18. Furue M. 2012. [Guidelines for atopic dermatitis -one point advice-]. Arerugi 61: 1719-1725. [Medline]

19. Chren MM, Lasek RJ, Sahay AP, Sands LP. 2001. Measurement properties of Skindex-16: a brief qualityof-life measure for patients with skin diseases. J Cutan Med Surg 5: 105-110. [Medline] [CrossRef]

20. Higaki Y, Kawamoto K, Kamo T, Horikawa N, Kawashima M, Chren MM. 2002. The Japanese version of Skindex-16: a brief quality-of-life measure for patients with skin diseases. J Dermatol 29: 693-698. [Medline] [CrossRef]

21. Joshi SS, Ortiz S, Witherspoon JN, Rademaker A, West DP, Anderson R, Rosenbaum SE, Lacouture ME. 2010. Effects of epidermal growth factor receptor inhibitorinduced dermatologic toxicities on quality of life. Cancer 116: 3916-3923. [Medline] [CrossRef]

22. Schneider L, Tilles S, Lio P, Boguniewicz M, Beck L, LeBovidge J. 2013. Atopic dermatitis: a practice parameter update 2012. J Allergy Clin Immunol 131: 295-299.

23. Fukuda K, Yoshihara S, Arisaka O. 2012. Arerugi 61(suppl) 1469, O8-4. (in Japanese)

24. Palomares O, Yaman G, Azkur AK, Akkoc T, Akdis M, Akdis CA. 2010. Role of Treg in immune regulation of allergic diseases. Eur J Immunol 40: 1232-1240. [Medline] [CrossRef]

25. Akdis CA, Blesken T, Akdis M, Wüthrich B, Blaser K. 1998. Role of interleukin 10 in specific immunotherapy. J Clin Invest 102: 98-106. [Medline] [CrossRef]

26. Ohmen JD, Hanifin JM, Nickoloff BJ, Rea TH, Wyzykowski R, Kim J, Jullien D, McHugh T, Nassif AS, Chan SC. 1995. Overexpression of IL-10 in atopic dermatitis. Contrasting cytokine patterns with delayed-type hypersensitivity reactions. J Immunol 154: 1956-1963. [Medline] 